\title{
A MICROSCALE VAPOR-FED FORMIC ACID FUEL CELL
}

\author{
$\underline{\text { J. Yeom }}^{[1]}$, R. S. Jayashree ${ }^{[2]}$, G. Z. Mozsgai ${ }^{[1]}$, A. Asthana ${ }^{[2]}$, E. R. Choban ${ }^{[2]}$, M. Mitchell ${ }^{[2]}$, \\ P. J. A. Kenis ${ }^{[2]}$, and M. A. Shannon ${ }^{[1] *}$ \\ ${ }^{[1]}$ Department of Mechanical and Industrial Engineering, University of Illinois, Urbana, IL 61801 \\ ${ }^{[2]}$ Department of Chemical and Biomolecular Engineering, University of Illinois, Urbana, IL 61801 \\ *mshannon@uiuc.edu
}

\begin{abstract}
A silicon-based microfabricated fuel cell running on formic acid vapor as a fuel has been developed to provide on-chip power for MEMS devices, without using any ancillary devices such as heaters, water management, air pumps, etc. As a demonstration instrument, an integrated silicon-based membrane electrode assembly and fuel evaporative structure was packaged in a plastic package to test the vapor-fed fuel cell concept. Initial results $(0.4$ $\mathrm{V}$ of the open circuit potential (OCP) and $2.3 \mathrm{~mW} / \mathrm{cm}^{2}$ of the peak power density) of the cell indicate that evaporation can potentially serve as a passive fuel delivery method for on-chip proton exchange membrane (PEM) fuel cells. The OCP is currently limited by anode reactions and the power density by both a slow anode catalyst $(\mathrm{Pt})$ and low evaporation rates. Continued improvements will raise the cell potential and power by incorporating higher kinetic catalysts, faster evaporative structures, and lower oxygen crossover in the gas permeability membranes.
\end{abstract}

\section{INTRODUCTION}

A worldwide effort is underway to develop micro-fuel cells that utilize liquid fuels, such as methanol and formic acid [1-4]. However, the direct contact of liquid fuel with the membrane electrode assembly (MEA) leads to the several drawbacks. Direct liquid fuel delivery needs some pumping action and gas extraction from the exhaust, where the byproducts such as $\mathrm{CO}_{2}$ form bubbles, potentially blocking fuel transport. Feedback systems are frequently used in large fuel cells to match the supply of fuel and water to the power load, and to avoid anode flooding. Reduced mass transport of the active fuel ingredients $(\mathrm{MeOH}, \mathrm{HCOOH}$, ethanol, etc.) can also be a problem associated with convection of fuel to the anode, and many research efforts try to alleviate it. These mitigation efforts become even more challenging at the microscale, as ancillary systems (pumps, gas extractors, water recycling, etc.) are harder to integrate into an efficient system.

Though little work has been done on passive vapor-fed fuel cells, the use of vapor phase fuel provides the following advantages over direct liquid fuel delivery. (1) Fuel is stored in concentrated form, so that higher effective energy density can be achieved. Liquids mixtures in direct feed are dilute $(\mathrm{MeOH} \sim 5 \%$ in $95 \% \mathrm{H}_{2} \mathrm{O}, \mathrm{HCOOH} \sim 40 \%$, etc). (2) No feedback system is required to deal with anode flooding. The condensation of vapor into liquid onto the anode is determined by the rate of consumption of fuel, driving the vapor off the equilibrium value of condensation occurring in the rest of the volume (determined by temperature). Thus, up to the maximum vaporization and condensation rate, the supply of fuel to the anode is automatic. (3) Exhaust gases can simply counter diffuse back from the anode as vapor condenses onto the MEA, thus preventing gas lock-up (bubble blocking), making exhaust/fuel separation an easier task if a membrane with different affinities to fuel and exhaust gases is available. (4) Flooding of the cathode with too much water is eliminated since water is not needed for evaporation. Methanol exhibits a higher vapor pressure $\left(\sim 95 \mathrm{mmHg}\right.$ at $\left.20^{\circ} \mathrm{C}\right)$ than formic acid $(\sim 33 \mathrm{mmHg}$ at $\left.20^{\circ} \mathrm{C}\right)$. However, the kinetics of methanol electro-oxidation is prohibitively slow at room temperature, which leads us to an alternative fuel, formic acid, which has a much higher kinetics than methanol [3]. A comparison of fuel cell performance of the two different fuel mixtures in liquid form can be found elsewhere [4].

In an effort to address these issues, we have developed and tested a microfabricated fuel cell running on formic acid vapor as a fuel. This microscale vapor-fed formic acid fuel cell has been prepared by various microfabrication technologies that will be described. An optical photograph of the Si-based fuel cell is shown in Fig. 1.

\section{EXPERIMENTAL DETAILS}

A complete silicon microfabricated vapor-fed fuel cell (Si$\mu$ VFFC) structure, as shown in Fig 1, comprises of two silicon electrodes, a proton conducting membrane, and a catalyst layer on electrodes. Two identical electrodes coated with $\mathrm{Au}$ and Pt-black were employed for both anode and cathode and sandwiched together to form a membrane electrode assembly (MEA).

$\mathrm{Si}-\mu$ VFFC electrodes were prepared using a series of MEMS fabrication processes adapted from our previous work. A $100 \mathrm{~mm}$ double-side polished silicon wafer (Silicon Quest; $500 \mu \mathrm{m}$ thick, $<100>$ oriented, $10 \Omega \cdot \mathrm{cm}$ of resistivity) was chosen as a base structure. To enhance current collection of the Si-substrates, a $1000 \AA$ Au layer was deposited using DC magnetron sputtering and patterned with a liftoff process. The front of the wafer was then coated with a polyimide spacer layer serving as both a dielectric layer for the electrodeposition of a catalyst and as the intermediate layer to promote a bonding between silicon substrate and Nafion ${ }^{\mathrm{TM}}$ membrane, the polymer electrolyte. In the second photolithography step, the front mesh pattern was aligned to the etch pits on the back of the wafer. Feedholes in the Si- $\mu$ VFFC electrode were created from the front of the wafer using a deeptrench reactive ion etcher (DRIE), and the back of the wafer was also etched by the same etching technique leaving a circular cavity. Figure 2(A) shows a scanning electron microscopy (SEM) image of the Si- $\mu$ VFFC electrode of a $50 \mu \mathrm{m}$ thick mesh with a $150 \mu \mathrm{m}$ pitch and $100 \mu \mathrm{m}$ square holes, facilitating rapid diffusion of fuel to the catalyst as well as transport of $\mathrm{CO}_{2}$ generated at the anode from the interface.

Often for PEM type fuel cells, the catalysts are applied to the membrane by painting Nafion-based inks containing Pt or Pt-alloy catalysts with carbon supports. However, this type of method is not compatible with an integrated membrane electrode assembly (MEA). Therefore, a catalytic layer of Pt-black (Alfa AESAR) was electroplated directly onto the $\mathrm{Au}$ current collector of both

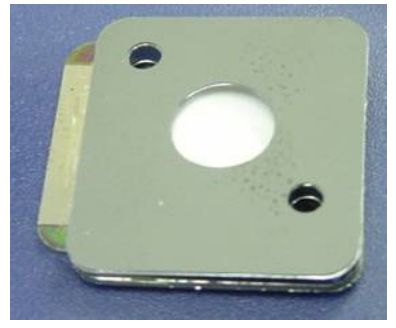

Figure 1. A photograph of a Si microfabricated vapor-fed fuel cell (Si$\mu V F F C$ ). The MEA and the Si wicking structures are bonded temporarily with a PDMS membrane.

Travel support has been generously provided by the Transducers Research Foundation and by the DARPA MEMS and DARPA BioFlips. 

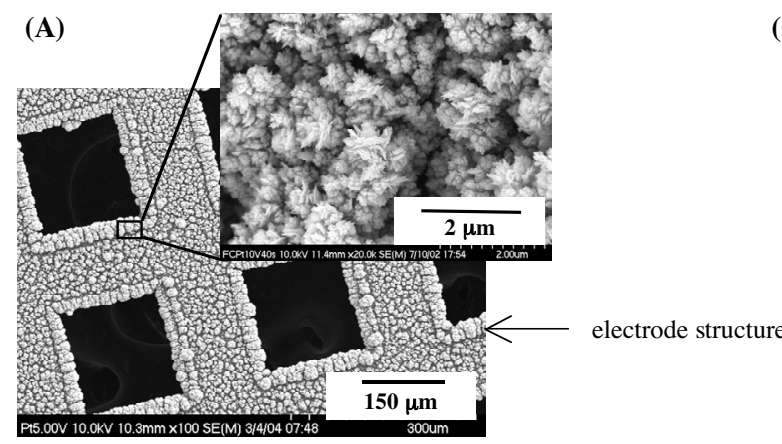

(B)
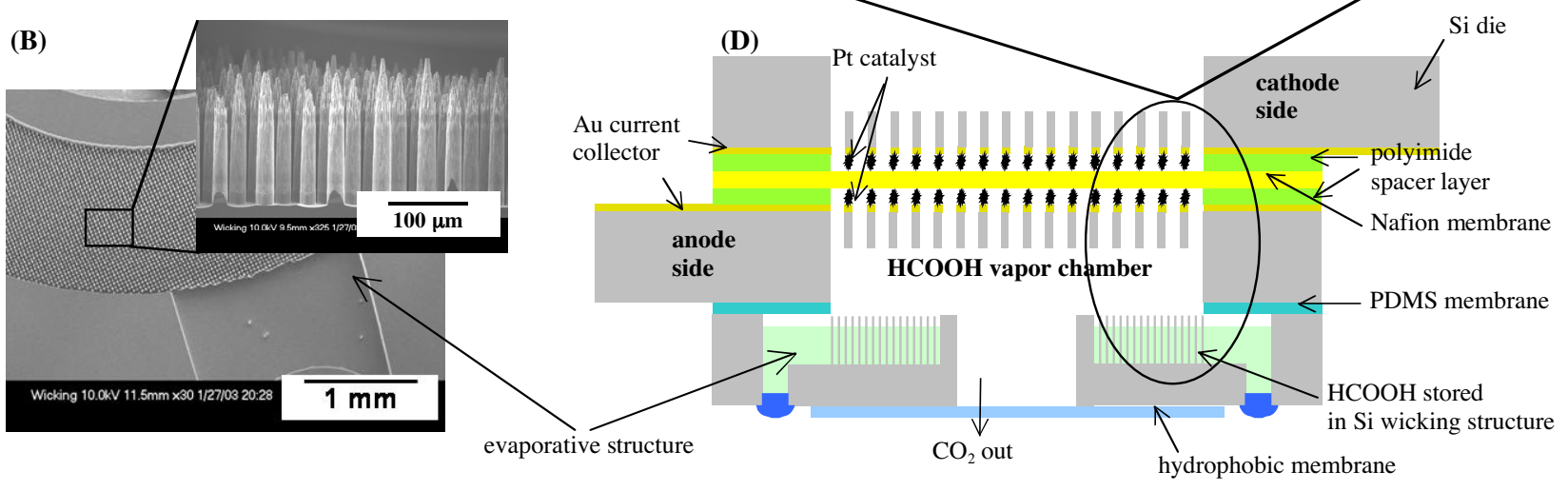

(C)

Figure 2. (A) A SEM of the DRIE-etched Si electrode structure deposited with Pt-black catalyst. The exploded view shows the dendritic growth of the catalyst due to high current density electrodeposition. (B) A SEM of the Si wicking structure: an array of DRIE etched posts of a pitch of $50 \mu \mathrm{m}, 15 \mu \mathrm{m}$ width, and around $250 \mu \mathrm{m}$ height (see the exploded view). (C) A SEM image of the cross-sectional view of the bonded fuel cell. The exploded view illustrates an excellent bonding between Si electrode and the Nafion $^{T M}$ membrane. (D) A schematic of the Si- $\mu$ VFFC including fuel delivery structure.

cathode and anode to reduce ohmic losses within the cell and to bring the catalyst into direct contact once assembled with both the current collector and the PEM. The plating bath consisted of $120 \mathrm{ml}$ DI water, $5 \mathrm{~g}$ dihydrogen hexachloroplatinate $\left(\mathrm{H}_{2} \mathrm{PtCl}_{6} \cdot 6 \mathrm{H}_{2} 0\right.$, Alfa AESAR), and $30 \mathrm{mg}$ of lead acetate $\left(\mathrm{Pb}\left(\mathrm{CH}_{2} \mathrm{COOH}\right)_{2} \cdot 3 \mathrm{H}_{2} 0\right.$, Alfa AESAR). High $\left(50\right.$ to $\left.100 \mathrm{~m}^{2} / \mathrm{cm}^{3}\right)$ surface areas were achieved by carrying out the deposition at relatively high current densities, $\sim 1 \mathrm{~A} / \mathrm{cm}^{2}$. Cyclic voltammetry measured an increase in surface roughness of approximately 500 . The dendritic growth of the Pt-black is shown in Fig. 2(A). This method, however, produces an undesirably high catalyst loading of over $5 \mathrm{mg} / \mathrm{cm}^{2}$, dictating a need for the thorough characterization of the catalyst deposition.

Two catalyst-coated electrodes are bonded onto either side of a Nafion $112^{\mathrm{TM}}$ membrane to form a Si MEA. Prior to bonding, the Nafion $112^{\mathrm{TM}}$ membrane was protonated by soaking it at $80^{\circ} \mathrm{C}$ in sequence in dilute $\mathrm{H}_{2} \mathrm{O}_{2}$, DI water, dilute $\mathrm{H}_{2} \mathrm{SO}_{4}$, and DI water for one hour each. The assembly was hot-pressed at $120^{\circ} \mathrm{C}$ under $\sim 200 \mathrm{~N} / \mathrm{cm}^{2}$ for 10 minutes.

High surface area evaporative (wicking) structures were fabricated to provide a high flux of formic acid into the anode. These Si wicking structures were etched in an ICP-DRIE Bosch process with a lithographically patterned mask of arrayed structures. Figure 2(B) shows an array of DRIE etched posts with a pitch of $50 \mu \mathrm{m}, 15 \mu \mathrm{m}$ width, and around $250 \mu \mathrm{m}$ height. According to recent studies by our group, the evaporation rate of formic acid depends on the area and perimeter of the microstructures [5]. The evaporation rates of formic acid from the microstructures range from 10.5 to $11.5 \mathrm{mM} / \mathrm{cm}^{2}-\mathrm{hr}$, which corresponds to a theoretical ideal power density of 280 to $310 \mathrm{~mW} / \mathrm{cm}^{2}$ at a cell potential of $0.5 \mathrm{~V}$.

The MEA and the Si-based wicking structure are bonded using polydimethysiloxane (PDMS) as an adhesive gasket.
Figures 2(D) and 2(C) show a schematic diagram of the integrated structure of a complete Si- $\mu$ VFFC and a SEM image of its crosssectional view, respectively. In order to prevent loss of fuel by vaporization, membranes with selective permeability for carbon dioxide (but impermeable to formic acid and water) were used. In this study, a $500 \mu \mathrm{m}$ thick PDMS membrane was used for the semi-permeable membrane, which was bonded on the exhaust port of the Si- $\mu$ VFFC.

All tests were performed at room temperature $(\sim 20 \mathrm{C})$ after conditioning. Conditioning was performed by holding the cell at $0 \mathrm{~V}$ and the OCP, each for 15 minutes. This procedure was repeated twice. During the conditioning, the flow rates of $\mathrm{H}_{2}$ and

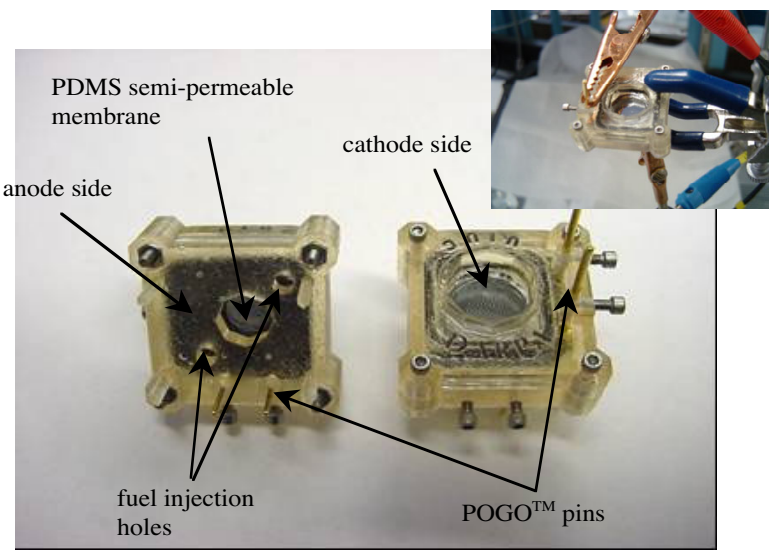

Figure 3. A photograph of the integrated Si- $\mu$ VFFC housed in a SLA package to make electrical connections. A simple test setup is shown in the top corner showing the stand-alone showing operation without ancillarv devices. 


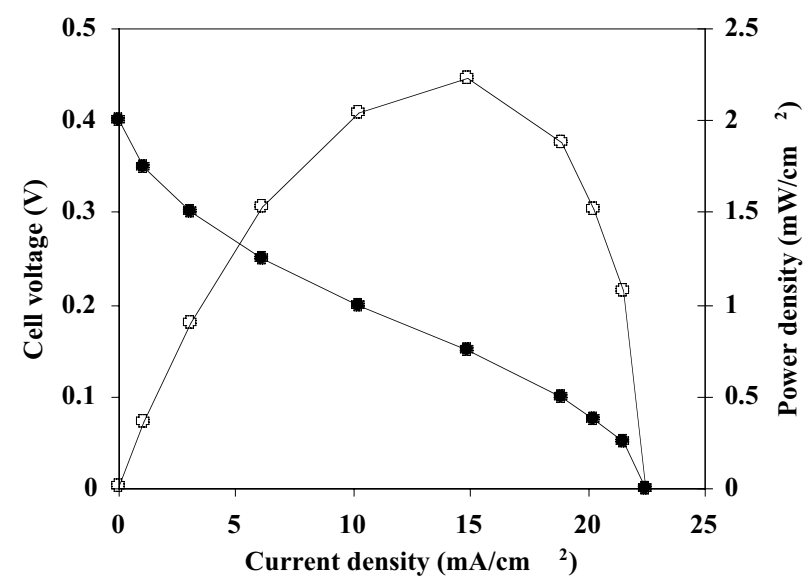

Figure 4. IV (dark circle) and power density (clear circle) profiles for the passive (vapor-fed) formic acid fuel cell, with $0.2 \mathrm{ml}$ of $10 \mathrm{M}$ formic acid evaporated at room temperature from the fuel Si wicking structure to the anode, while cathode is open to ambient.

$\mathrm{O}_{2}$ were $10 \mathrm{sccm}$. This preconditioning was required to properly hydrate the membrane, as significant drying occurs during the bonding process. The MEA was placed in a plastic housing made using a stereolithography apparatus (SLA, 3-D Systems) in order to make the external electrical connections for the experiments. Figure 3 shows the anode and cathodes side of the SLA package with a Si- $\mu$ VFFC. An amount of 20 to $40 \mu \mathrm{L}$ of $10 \mathrm{M}$ formic acid solution (prepared from ACS grade, 96\%, ACROS Organics) was injected in through a PDMS plug in the Si- $\mu$ VFFC. Various concentrations of $\mathrm{HCOOH}$-water mixtures were fed into the $\mathrm{Si}$ wicking structure, to study the effect of concentration on the performance of the cell. The cathode side is open to air. All voltage and current measurements were made using a potentiostat (Autolab PGSTAT 30) to regulate the load on the cell. The I-V curves were generated by holding the cell at various potentials.

\section{RESULTS AND DISCUSSION}

The Si MEAs were operated as hydrogen PEM fuel cells before bonding the MEAs with the evaporative structure to form a $\mathrm{Si}-\mu$ VFFC, in order to verify their performance. These $\mathrm{H}_{2}-\mathrm{O}_{2}$ MEAs delivered an open circuit potential of 0.95 to $0.98 \mathrm{~V}$, and a short circuit current density of 80 to $100 \mathrm{~mA} / \mathrm{cm}^{2}$, matching the results in our previous study [4]. We have made at least 5 different $\mathrm{Si}-\mu$ VFFCs and compared the performance of the cells. The open circuit potentials and peak power densities varied within $10 \%$ from cell to cell.

Figure 4 shows the current density, cell potential, and power density for the Si- $\mu$ VFFC with $10 \mathrm{M}$ formic acid as the fuel, and quiescent air as the oxidizer. Measured currents were normalized to the nominal electrode area of $0.44 \mathrm{~cm}^{2}$ to obtain the current density. The open circuit potential (OCP) was $0.4 \mathrm{~V}$ and the maximum power density obtained under these conditions was $2.3 \mathrm{~mW} / \mathrm{cm}^{2}$. These values are comparatively lower than those reported in our previous forced fed formic acid fuel cell studies $\left(0.55 \mathrm{~V}\right.$ of the OCP and $17 \mathrm{~mW} / \mathrm{cm}^{2}$ of the peak power density) [4]. Fukunaga et al. have reported lower OCP in the case of vapor feed direct methanol fuel cells [6]. They suggest that the chemical potential of methanol in the vapor phase is lower than that for liquid if the partial pressure of methanol is lower than the saturated vapor pressure. We speculate that the lower OCP in the current case could be due to similar reasons, as well as a mixed potential from the presence of oxygen at the anode. The current method of injecting fuel through the PDMS ports can admit significant

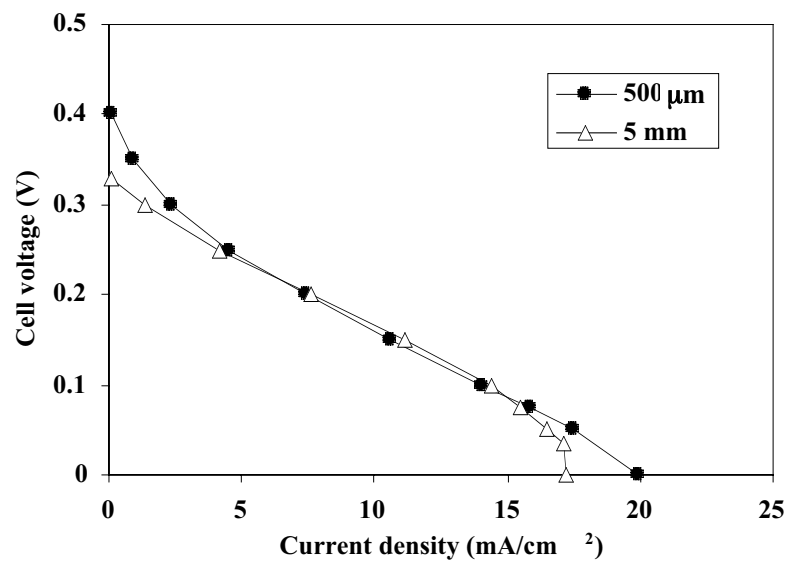

Figure 5. IV curves for Si- $\mu$ VFFCs with a different thickness of PDMS membrane between the anode and the Si wicking structure, while running on $0.04 \mathrm{ml}$ of $10 \mathrm{M}$ formic acid vapor with the cathode open to ambient air.

amounts of air to the anode side. In addition, the current and power densities for the Si- $\mu$ VFFC are almost an order of magnitude lower than those of LF-FAFC. This lower current may be due to a mass transport limit of the evaporating formic acidwater mixture. It is also possible that the quiescent air-fed cathode is limiting the performance somewhat in comparison to the forced oxygen LF-FAFC. The crossover of fuel to the cathode from the anode can also be different than LF-FAFC. Finally, the overall kinetics of the catalysts for the condensing vapor fuel mixture at the anode may be quite different than that for a forced liquid flow.

One major issue with these Si $\mu$ VFFCs is whether the fuel mixture is delivered to the anode as a vapor and not as a liquid. If the liquid fuel injected into the Si wicking structure makes direct contact with the anode, the cell performance can be vastly different from the fuel being delivered as a vapor from the wicking structure. To confirm the utilization of vapor in these cases, cells with larger distances between MEA and the wicking structures were studied, and different amounts of fuel were injected. The increased distance was achieved by using a thicker PDMS block between the MEA and the evaporative structure to further separate the fuel reservoir from the anode when the same quantity $(0.04 \mathrm{ml})$ and concentration $(10 \mathrm{M})$ of the fuel mixture is injected. Figure 5 shows the polarization (I-V) curve for the Si- $\mu$ VFFC with the PDMS blocks of $500 \mu \mathrm{m}$ and $5 \mathrm{~mm}$. The performance of the cells

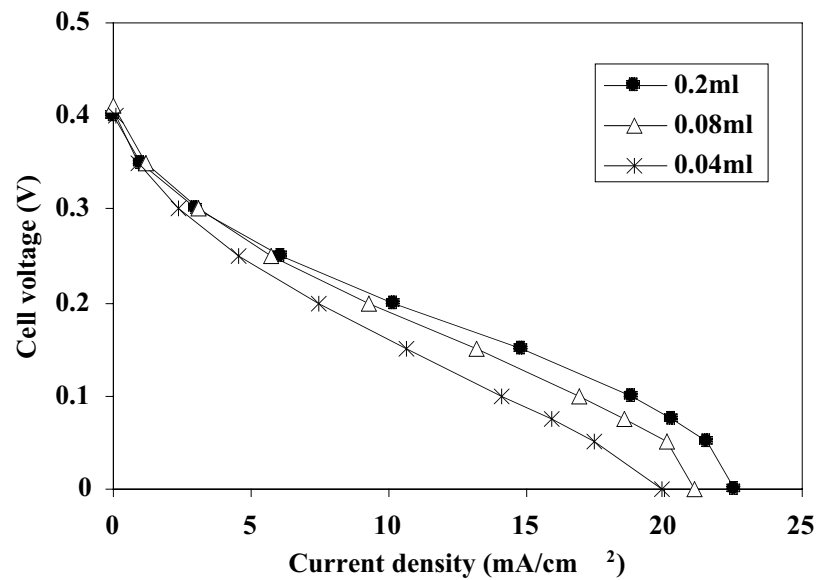

Figure 6. IV curves for Si- $\mu V F F C$ 's with various amount of $10 \mathrm{M} \mathrm{HCOOH}-\mathrm{H}_{2} \mathrm{O}$ mixture (from $0.04 \mathrm{ml}$ to $0.2 \mathrm{ml}$ ) when the PDMS membrane thickness is fixed at $500 \mu \mathrm{m}$. No drastic change in cell performance ensures the fuel being delivered to anode as a vapor. 


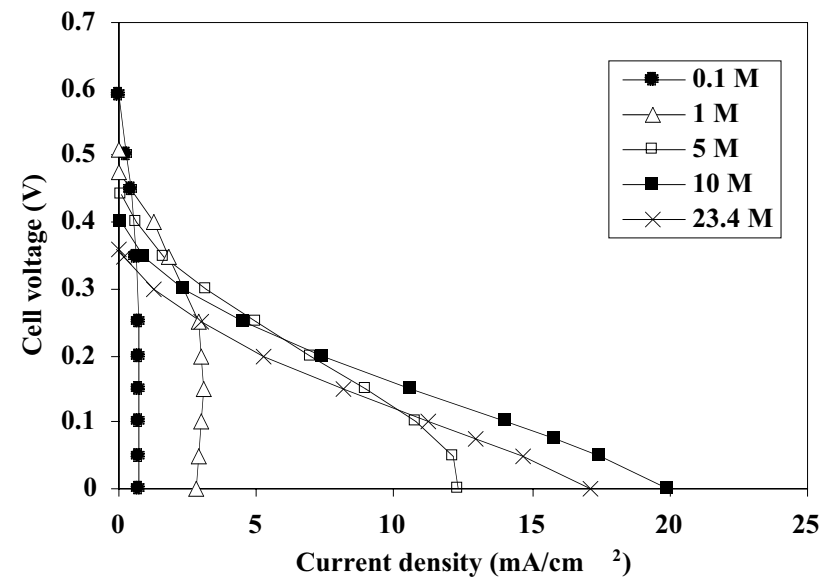

Figure 7. The IV curves for Si- $\mu V F F C s$ with a wide range of concentration of $\mathrm{HCOOH}-\mathrm{H}_{2} \mathrm{O}$ mixtures (from $0.1 \mathrm{M}$ to 23.4 $M)$. All testing was performed at room temperature $\left(\sim 20^{\circ} \mathrm{C}\right)$ with an ambient air-breathing cathode.

did not vary with the distance between the MEA and the wicking structures, indicating that our fuel cells work in a vapor phase regime. In addition, for a fixed PDMS layer $(500 \mu \mathrm{m})$, the amount of the $10 \mathrm{M} \mathrm{HCOOH}-\mathrm{H}_{2} \mathrm{O}$ mixture injected was varied from 0.04 $\mathrm{ml}$ to $0.2 \mathrm{ml}$. No significant change in the cell performance is observed in Fig. 6. Therefore, we believe that the fuel mixture is being delivered as a vapor in the $\mathrm{Si}-\mu \mathrm{VFFC}$.

Another major issue with the $\mathrm{Si}-\mu \mathrm{VFFC}$ is the removal of the product $\mathrm{CO}_{2}$ without the loss of formic acid and water mixture from the anode side of the fuel cell. In addition, as noted above, the exclusion of oxygen from the anode is important to avoid mixed potentials at the anode. Our approach in this $\mathrm{Si}-\mu \mathrm{VFFC}$ is to employ a membrane that is permeable to $\mathrm{CO}_{2}$, but is relatively impermeable to $\mathrm{O}_{2}, \mathrm{H}_{2} \mathrm{O}$ and $\mathrm{HCOOH}$. We found that PDMS met these requirements and we tested a number of membranes with different thicknesses. The permeability of the $400 \mu \mathrm{m}$ thick PDMS membrane utilized in this current work was measured to be $3.96\left(10^{-4}\right)\left\{\mathrm{cm}^{3}(\mathrm{STP}) \cdot \mathrm{cm} / \mathrm{cm}^{2} \cdot \mathrm{sec} \cdot(\mathrm{cmHg})\right\}$ for $\mathrm{O}_{2}$ and $2.55\left(10^{-3}\right)$ $\left\{\mathrm{cm}^{3}(\mathrm{STP}) \cdot \mathrm{cm} / \mathrm{cm}^{2} \cdot \mathrm{sec} \cdot(\mathrm{cmHg})\right\}$ for $\mathrm{CO}_{2}$ at an inlet gas pressure of 100 torr. The permeability of $\mathrm{CO}_{2}$ is found to be 5 times higher than the $\mathrm{O}_{2}$ permeability, which makes PDMS an initial candidate for the semi-permeable membrane for the anode.

The Si- $\mu$ VFFC's were also studied as a function of formic acid concentration ranging from $0.1 \mathrm{M}$ to $23.4 \mathrm{M}$ ( $88 \%$ by weight). The IV curves of Si- $\mu$ VFFC with various concentrations of formic acid are shown in Fig. 7. As the concentration of formic acid increases, the current density increases to a maximum at about $10 \mathrm{M}$, which is consistent with forced LF-FAFC results [3]. The OCP, however, drops monotonically with increasing concentration, as seen in Fig. 8. The peak power density of these cells, though, increases with concentration until $\sim 10 \mathrm{M}$ concentration is reached, as shown in Fig. 8. The low power density of these cells at the lowest concentrations of formic acid could be due to mass transport limitations of the formic acid from the wicking structure to the anode. However, it is interesting to note that the cell potentials were higher with lower concentrations of formic acid.

At the highest formic acid concentrations tested, the cell performance decays slightly, which is significant since we would prefer to maximize the energy density of the fuel using high concentrations of formic acid. There are many potential mechanisms for this decay [3], but the dehydration of the membrane from the low water content at the anode at high formic acid concentrations will reduce proton conductivity through the Nafion, thereby reducing the current flow and power output. More

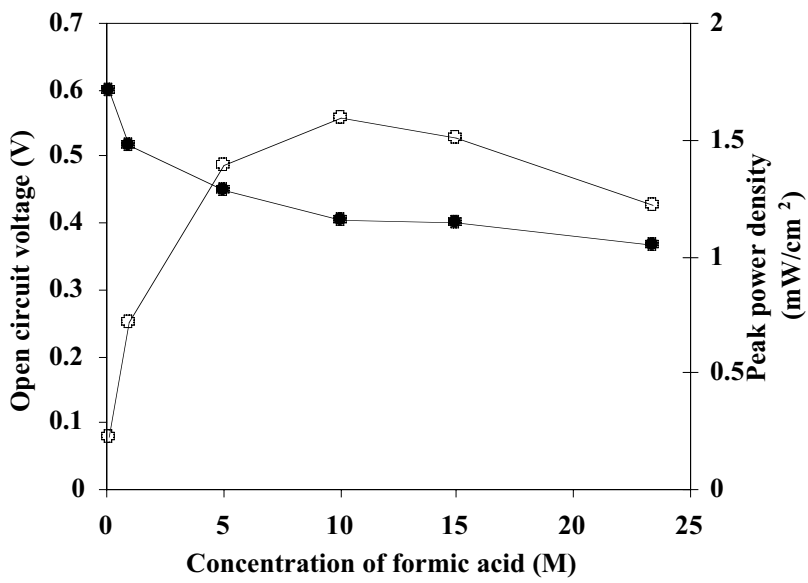

Figure 8. Plots of formic acid feed concentration vs. OCP (dark circle) and formic acid feed concentration vs. peak power density (clear circle).

experiments are being performed to understand the mechanisms associated with each of the unique aspects of operating vapor-fed fuel cells with formic acid as the fuel.

\section{ACKNOWLEDGEMENT}

The fuel cell work was supported by the Defense Advanced Research Projects Agency under US Air Force Grant F33615-01C2172. All SEM work was conducted in the Center for Microanalysis of Materials, in the Frederick Seitz Material Research Laboratory, University of Illinois, which is partially supported by the U.C. Department of Energy under grant DEFC0291-ER45439. Any opinions, findings, and conclusions or recommendations expresses in this publication are those of the authors and do not necessarily reflect the views of the Department of Energy, the U.S. Air Force, or the Defense Advanced Research Projects Agency.

\section{REFERENCE}

1. S. C. Kelley, G. A. Deluga, and W. H. Smyrl, "Miniature Fuel Cells Fabricated on Silicon Substrates," AlChE J., 48, 1071-1082 (2002).

2. W. Y. Sim, G. Y. Kim, and S. S. Yang, "Fabrication of Micro Power Source (MPS) Using a Micro Direct Methanol Fuel Cell (DMFC) for the Medical Application," IEEE Intl. Conf. On MEMS, Tech. Digest, 14, 341-344 (2001).

3. C. A. Rice, S. Ha, R. I. Masel, P. Wazczuk, A. Wieckowski, and T. Barnard, "Direct Formic Acid Fuel Cells," J. Power Sources, 111, 83-89 (2002).

4. J. Yeom, G. Z. Mozsgai, A. Asthana, B. R. Flachsbart, P. Waszczuk, E. R. Choban, P. J. A. Kenis, and M. A. Shannon, "A Silicon Microfabricated Direct Formic Acid Fuel Cell," 1st International Conference on Fuel Cell Science, Engineering and Technology, Rochester, NY, 4/21-23/03, ASME (2003).

5. A. Asthana, E. R. Choban, M. Mitchell, R. S. Jayashree, and P. J. A. Kenis, "Formic Acid Evaporation from Microstructures Towards Passive Fuel Delivery Elements for Micro Fuel Cells", submitted.

6. H. Fukunaga, T. Ishida, N. Teranishi, C. Arai, and K. Yamada, "Impedance of Vapor Feed Direct Methanol Fuel Cells Polarization Dependence of Elementary Processes at the Anode", Electrochimica Acta, 49, 2123-2129 (2004) 